2. To: (Receiving organization)

Information Resource

Management

5. Proj./Prog./Dept./Div.:

2Z-96-2749

8. Originator Remarks:

For USQ see PFP-95-29

11. Receiver Remarks:
3. From: (originating organization) PFP Facilities Systems Engineering

6. Design Authority/ Design Agent/Cog. Engr.:

R.D. Keck
11A. Design Baseline Document? [] Yes [X] No

4. Related EDT NO.:

$N / A$

7. Purchase Order No.:

N/A

9. Equip./Component No.:

N/A

10. System/Bldg./Facility: 12B/2721-Z

12. Major Assm. Dug. No.:

H-2-77029 sht al1

13. Permit/Permit Application Ho.: N/A

14. Required Response Date: N/A

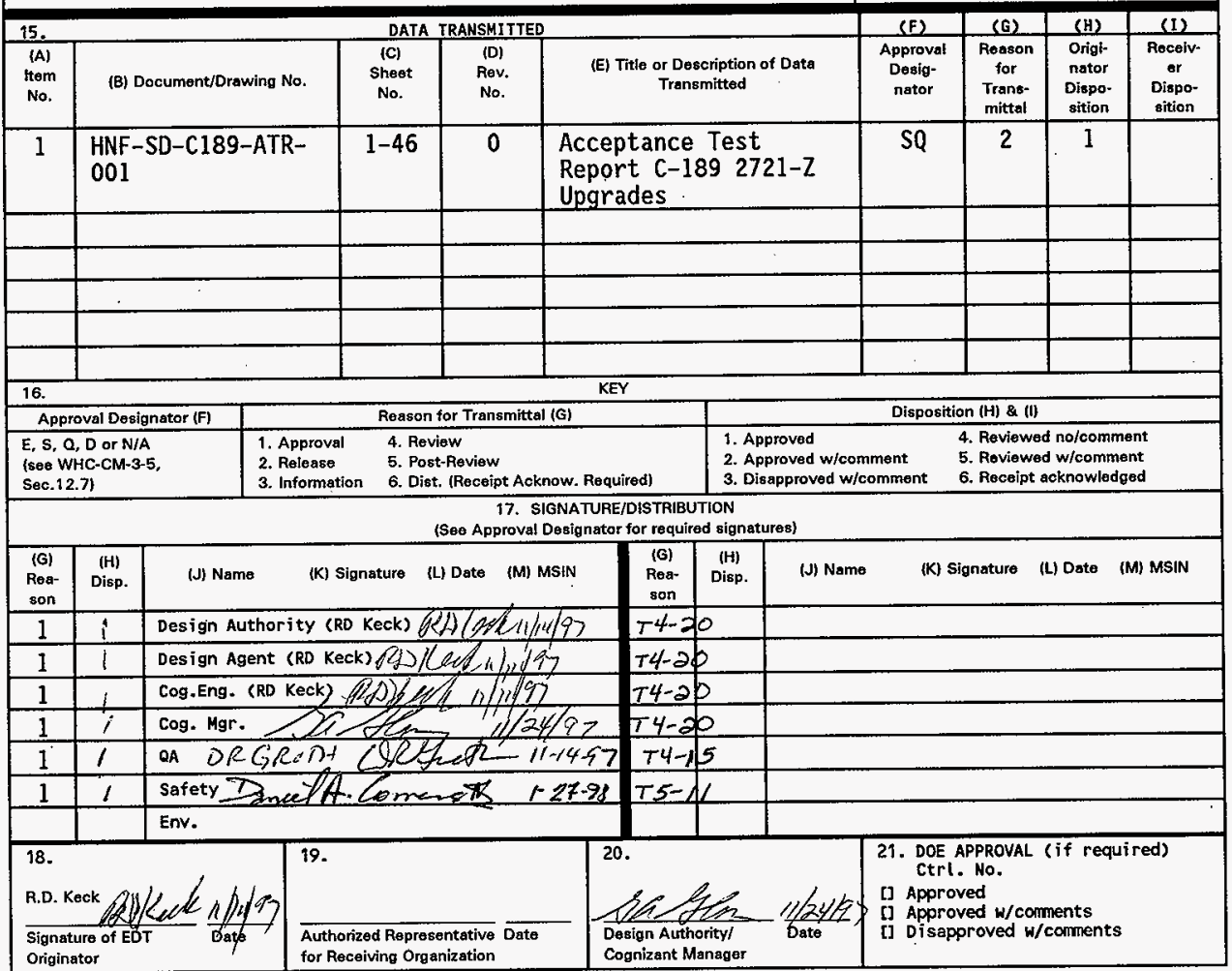

BD-7400-172-2 (05/96) GEF097 
HNF-SD-C189-ATR-001, Rev. 0

\section{Acceptance Test Report 2721-Z Upgrades}

R. D. Keck

Babcock \& Wilcox Hanford Company, Richland, WA 99352

U.S. Department of Energy Contract DE-AC06-96RL13200

EDT/ECN: 141073

Org Code: 15510

UC: 515

B\&R Code: EW7002010

Charge Code: K6197

Total Pages: 46

Key Words: Generators, Backup Power, Control

Abstract: Acceptance testing for control upgrades to $2721-Z$ is reported for verification of the new controls, power switching equipment and wiring.

MICON is a trademark of MICON Systems, Inc

IRADEMARK DISCLAIMER. Reference herein to any specific commercial product, process, or service by trade name, trademark, manufacturer, or otherwise, does not necessarily constitute or imply its endorsement, recommendation, or favoring by the United States Government or any agency thereof or its contractors or subcontractors.

Printed in the United States of America. To obtain copies of this document, contact: Document Control Services, P.0. Box 950, Mailstop H6-08, Richland WA 99352 , Phone (509) 372-2420;
Fax (509) 376-4989.
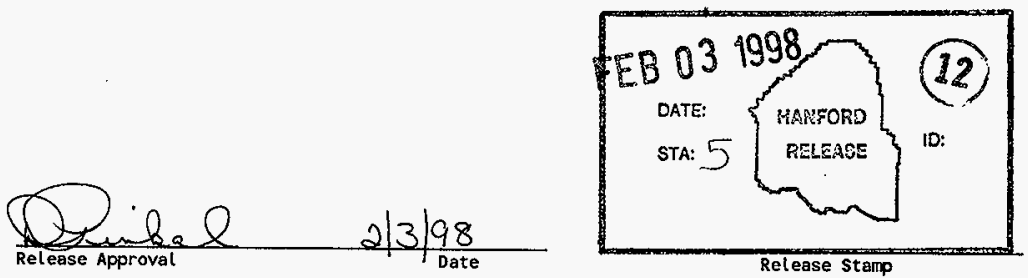


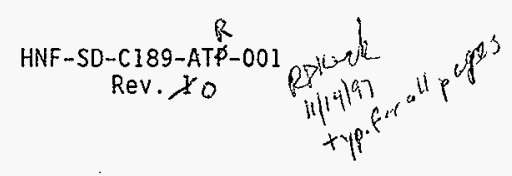

Acceptance Test Procedure 2721-Z Upgrades

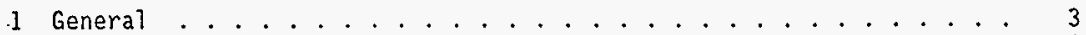

1.1 Scope . . . . . . . . . . . . . . . . . 3

1.2 References...................... . 3

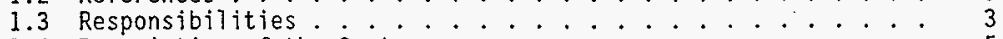

1.4 Description of the System .............. . . . 5

1.5 Test Conditions and Equipment Required........... . . 6

1.6 Change Control ................. . . 6

1.7 Execution .. . . . . . . . . . . . . . . . . . 6

1.8 Exceptions...................... . . . . 6

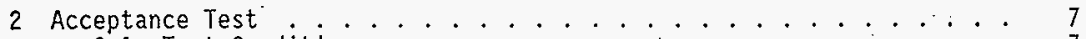

2.1 Test Conditions . . . . . . . . . . . . . . 7

2.2 Lamp Test . . . . . . . . . . . . . . . . . . . . 8

2.3 Sequence Lamps . . . . . . . . . . . . . . . . . . . . . . . 8

2.4 Mode switches . . . . . . . . . . . . . . . . . 9

2.5 Generator 1 Controls and Alarms . . . . . . . . . . . . 9

2.6 Generator 2 Controls and Alarms . . . . . . . . . . . . . 13

2.7 Generator 3 Controls and Alarms . . . . . . . . . . . . 16

2.8 Miscellaneous Inputs and Outputs............. 19

2.8.1 Test Switches . . . . . . . . . . . . . . 19

2.8.2 Automatic Generator Load Controlier . . . . . . . 20

2.8.3 Signals from 234-52 Transfer Control Panel . . . . . 21

2.8.4 234-5Z Breaker Position Indications . . . . . . . . . . 23

2.8.5 Generator Bus Load Circuit Breaker Position/Control . 24

2.8.6 Panel NP-VF-1-3 (CB 3) Position Indication and Control.................... 25

2.8.7 ATS position indications............ . . 26

2.8.8 Over/Under Voltage/Frequency and Reset......... . 27

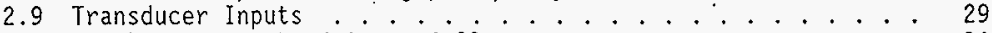

2.10 Back-up Power Load Start Calls . . . . . . . . . . . . 34

2.10.1 Set-up . . . . . . . . . . . . . . . 34

2.10 .2 ATS-3 Start Call ............ . . 34

2.10.3 ATS-4 Start Call ................ . . 34

2.10.4 234-5Z Start Call............... 35

$2.10 .52736-\mathrm{ZB}$ Start Cal1............ 36

2.10 .6 ATS-2 Start Call . . . . . . . . . . . . . . 36

3 EXCEPTIONS TO ACCEPTANCE TEST . . . . . . . . . . . . . . . . 38

4 Test parties. . . . . . . . . . . . . . . . . . . . . 41

5 TEST APPROVAL . . . . . . . . . . . . . . . . . . . . . . . . 44 


\section{$R$ \\ HNF-SD-C189-ATధ-001 \\ Rev. $y 0$ \\ Acceptance Test Procedure \\ 2721-Z Upgrades}

\section{General}

\subsection{Scope}

This test procedure provides instructions for acceptance testing of modifications to the 2721-Z diesel generator system made by Project C-189. The modifications include 1) replacing the generator NUMA-LOGIC controller with connection to the PFP distributed control system (DCS), 2) replacing ATS1 with a breaker switching scheme for 2736-ZB backup power and 3) providing a method for generator load and system testing.

\subsection{References}

Drawings

H-2-827908, Electrical Phase 3 Plan

H-2-827909, Electrical Phase 3 One Line Diagram

H-2-827910, Electrical Phase 3 Details \& Elevations

Engineering Change Notices ( $E C N$ )

C189-043, MICON Information

C189-046, MICON Information

C189-013, Essential Drawings

Prior to final test approval, enter ECNs written against this ATP on the exceptions page.

\subsection{Responsibilities}

\subsubsection{Genera?}

Each company or organization participating in this ATP will designate personnel to assume the responsibilities and duties as defined herein for their respective roles. The designees shall become familiar with this ATP and the systems involved to the extent that they can perform their assigned duties.

\subsubsection{Project Engineer}

Acts as liaison between the participants in acceptance testing.

Distributes the approved testing schedule before start of testing.

Schedules and conducts a pretest kickoff meeting with test participants when necessary.

Notifies the persons supporting the test 2 days before the start of testing. 


$$
\begin{gathered}
R \\
\text { HNF-SD-C189-ATP-001 } \\
\text { Rev. YO }
\end{gathered}
$$

Notifies concerned parties when a change is made in the testing schedule.

Signs Test Approval page when test is approved and accepted.

Takes necessary action to clear exceptions to the test.

1.3.3 Test Director (PFP Electrical Power and Control Cognizant Engineer or MICON Cognizant Engineer)

Coordinates and directs acceptance testing.

Confirms that field testing and inspection of the system or portion of the system to be tested has been completed.

Stops any test which, in his.or her judgment, may cause damage to the system until the problem has been resolved.

After verifying there is no adverse impact, may aiter the sequence in which systems or subsystems are tested.

Ensures that required environmental conditions are maintained.

If a test is to be suspended for a period of time, ensures that the system is left in a safe mode.

Before restarting suspended test, reverifies the test prerequisites.

Initiates ECNS to document required changes to the ATP.

Reviews recorded data, discrepancies, and exceptions.

Obtains information or changes necessary to clear or resolve objections during the performance of the test.

Signs Test Approval page when test has been performed.

Obtains required signatures on the ATP Master prior to reproduction and distribution.

1.3.4 WITNESSES (Provided by Participating Organizations. One witness shall be a Title III acceptance inspector.)

Witness the tests.

Review results of testing.

Assist the Test Director when requested.

Title III acceptance inspector sign Test Approval page when test has been performed. 


$$
\begin{gathered}
\text { RNF-SD-C189-ATṔ-001 } \\
\text { Rev. } \not 0
\end{gathered}
$$

\subsubsection{Recorder (Provided by FDNW)}

Records test instrument identification numbers and calibration expiration dates, as required.

Initials and dates every test step on the Field copy as it is completed next to the step number or on a data sheet, when provided. Records test data. On data sheets where there is not room for both the initial and date, date may be entered at bottom of column.

Records exceptions on exception form. Uses additional exception forms as needed. Notifies the Test Director at time the exception is made.

After test is finished, assigns alpha numeric page numbers to added exception forms. Records page numbers in the Table of Contents.

Transfers Field copy entries for each step to the Master in ink or type, signs, and dates. Transmits the completed Master to the Test Director

for approval signature routing.

\subsubsection{Test Operator}

Performs test under direction of the Test Director.

Provides labor, equipment, and test instruments required for performing tests which have not been designated as being provided by others.

Requests in writing from the Test Director those services, materials, or equipment that have been designated as being supplied by others.

Confirms that all equipment required for performing test will be available at the start of testing.

\subsubsection{Lead Design Engineer}

Evaluate results.

Sign for Approval on Test Approval page.

\subsection{Description of the System}

Project C-189 is modifying the 2721-Z diesel generators to: 1) replace the generator NUMA-LOGIC controller with connection to the PFP distributed control system (DCS), 2) replace ATS-1 with a breaker switching scheme for 2736-ZB backup power and 3) provide a method for generator load and system testing.

The testing will focus on verifying the connections to the DCS, verifying the hardwired generator controls and current connections to the DCS were not impacted by the modifications and verifying the operability of the DCS configuration software in an off-line mode. 


\subsection{Test Conditions and Equipment Required}

Supplied by Test Operator unless otherwise noted.

1.5.1 Voltohmmeters (VOM):

Instrument No. $840-45.08-068$ Expiration Date 4.9 .98

1.5.2 Ammeters: 0 to 5 Amp.

Instrument No. $840-45-02-013$

1.5.3 Power Source; 0 to 60 Hertz

1.5.4 Jumper wires connected to a switch.

1.5.5 Current sources; 0 to 1 madc, 0 to 5 amp $A C$

1.6 Change Control

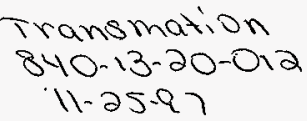

Technical changes to this test procedure shall be authorized by an ECN. Administrative changes, including order of turning activating inputs or verifications, may be authorized by the Electrical Power and Control or MICON Cognizant Engineer and shall be recorded in black ink on the instruction page. Changes sha7l be signed by the Cognizant Engineer and the QA Engineer or his representative. Record these changes on the exception sheet in appendix A.

\subsection{Execution}

\subsubsection{Occupational Safety and Health}

Individuals shall carry out their assigned work in a safe manner to protect themselves and others from undue hazards and to prevent damage to property and environment. Facility line managers shall assure the safety of activities within their areas to prevent injury, property damage, or interruption of operation. Performance of test activities shall always include safety and health aspects. A pre-job safety meeting shall be held and this ATP discussed with the personne? supporting the test.

In order to accomplish the work in this ATP, it is necessary to have the equipment or circuit energized. Complete testing requires installation and removal of jumpers to 24 VDC circuits. Verification of no exposed voltages above 50 volts in the area of installation and removal of jumpers is required.

\section{I.8 Exceptions}

Exceptions to the required test results are sequentially numbered and recorded on the exception forms. 


$$
\begin{gathered}
\text { HNF-SD-C189-ATP-001 } \\
\text { Rev. \O }
\end{gathered}
$$

Technical Errors/exceptions in the ATP itself shall NOT be processed as test exceptions (see Section 1.6 CHANGE CONTROL).

Number each exception sequentially as it occurs and record it on the exception form.

Enter disposition to resolve each exception when such determination is made.

\section{Acceptance Test}

NOTE: IF A PIECE OF EQUIPMENT FAILS OR DOES NOT PERFORM AS DESIGNATED BY THIS DOCUMENT, THE TEST COORDINATOR MAY MOVE TO ANOTHER PART OF THIS PROCEDURE OR ANOTHER PIECE OF EQUIPMENT TO CONTINUE TESTING WHILE TROUBLESHOOTING AND REPAIR IS COMPLETED UNDER WORK PACKAGE. CONTROL ON THE FAILED OR UNSATISFACTORY EQUIPHENT.

\section{Doles 2.1 Test Conditions}

\subsection{7}

\subsubsection{Energy Boundaries}

ODO 2721-Z Switchgear Circuit Breaker 1 OPEN and L\&T installed ow F8X309 Racked out and L\&T installed.

उo Over tag on back-up power junction box for ATS-3/4 (cables from 2721-z (82).

OOW Over tag on ATS-2 (cables from 2721-Z CB3).

QuS NP-VF-1-3 (CB 3) Closed and remote close control locked out

\section{QDe) 2.1.2 Equipment Configuration}

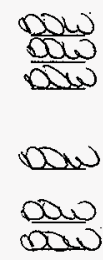

2721-Z Switchgear Circuit Breakers 2, 3 and 4 OPEN.

2721-Z Generators 1,2 and 3 mode switches in AUTO position. In Switchgear master section verify the following wires for NP-VF-1-3 (CB 3) are lifted 7 ifted and taped 0119 (TB15), 711 (TB15) and 0104 (TB13).

Circuit breakers $\# 26$, \#28, \#30, \#31, \#33, \& \#35, panel LPEP-5, 2721-Z CLOSED.

The positive leads on diesel generator batteries connected. Verify 24 vdc power supply in 2721-Z switchgear master section and generator batteries are operating at less than $50 \mathrm{vdc}$.

Da) 2.1 .3 Notifications

8-27-9) Dou Notify B.E.D. Shift Operations Manager (PAX 227) DOWNotify MICON Control Room, PAX 348/373-0084 that DCS alarms will be generated and verification of DCS values will be required.

NOTE: Sections 2.2 through 2.9 may be done in any order at the Test Director's discretion.

NOTE: Fuel Level must be taken in accordance with 20-060-210 each day before running a diesel generator and after the last run of the day. 
HNF-SD-C189-ATP-001

Rev. Xo

\section{Dow 2.2 Lamp Test}

8.2.0.7.

Depress lamp test pushbutton on Master Section of the Switchgear and verify the following lamps on the top section of the panel illuminate

QOD GEN 1 AVAILABLE

DU. GEN 2 AVAILABLE

DUW GEN 3 AVAILABLE

DUWO GEN 1 TROUBLE

DU GEN 2 TROUBLE

DON GEN 3 TROUBLE

OQW GEN 1 ON LINE

DUW GEN 2 ON LINE

DUN GEN 3 ON LINE

DON 1-2-3 SEQUENCE

DOW 2-3-1 SEQUENCE

DUQ 3-1-2 SEQUENCE

DNo GEN 1 LOAD SHED

DOW GEN 2 LOAD SHED

DOU GEN 3 LOAD SHED

DOR GEN TEST

Diw U/0 Volt

ODNU/0 Frequency

$\frac{\text { ODu }}{6.22-9} 2.3$ Sequence Lamps

DoN Depress the 1-2-3 sequence switch/lamp on the Master Section of the Switchgear

Du Verify the $1-2-3$ sequence lamp $i 11$ uminates and stays $i 11$ uminated after the switch is released.

Q. Verify the 1-2-3 mode is indicated on the DCS 2721-Z generator status display.

Ono Depress the 2-3-1 sequence switch/lamp on the Master Section of the Switchgear

OD. Verify the 2-3-1 sequence lamp 11 luminates and stays $i 11$ uminated after the switch is released.

Do Verify the 2-3-1 mode is indicated on the DCS 2721-Z generator status display.

Mo) Depress the 3-1-2 sequence switch/lamp on the Master Section of the Switchgear

OC. Verify the 3-1-2 sequence lamp illuminates and stays illuminated after the switch is released.

De verify the 3-1-2 mode is indicated on the DCS 2721-z generator status display. 


$$
\begin{gathered}
\text { HNF-SD-C189-ATP-001 } \\
\text { Rev. } 100
\end{gathered}
$$

\section{Sou 2.4 Mode switches}

0.229

QDW Verify three generator mode switches are in the AUTO position.

DOW Verify the three GEN X AVAILABLE lamps on the Master Section of the Switchgear are illuminated.

DW Turn the mode switch on generator 1 to the OFF/RESET position and verify the GEN I AVAILABLE 1 amp is extinguished and the GEN I TROUBLE. 1 amp is illuminated.

DOW) Verify on the DCS generator status display shows generator 1 is off.

DQW Turn the mode switch on generator 2 to the OFF/RESET position and verify the GEN 2 AVAILABLE 7 amp is extinguished and the

GEN 2 TROUBLE lamp is illuminated.

OOW Verify on the DCS generator status display shows generator 1 and 2 are off.

OQW Verify a DCS GEN_OFLN alarm was received.

Dow Turn the mode switch on generator 3 to the OFF/RESET position, and verify the GEN 3 AVAILABLE lamp is extinguished and the

GEN 3 TROUBLE lamp is illuminated.

DOW Verify that the ocs generator status display shows the three generators in the off mode.

QDe Verify a DCS GEN_OFLN alarm was received.

D.) Turn the mode switch on generator 2 to the AUTO position and verify the GEN 2 AVAILABLE lamp is illuminated and the

GEN 2 TROUBLE 7 amp is extinguished.

DOW Verify a DCS GEN_OFLN alarm was received.

DOW Return the remaining two mode switches to the AUTO position and verify the GEN $X$ AVAILABLE lamps are $i l l$ uminated and the GEN $X$ TROUBLE are extinguished.

OON Verify a DCS GEN_ONLN alarm was received.

DOW Verify that the OCS generator status display shows the three generators in the auto mode.

Dow 2.5 Generator 1 Controls and Alarms 8. 258

DOe 2.5.1 Low Battery Voltage

DW Install insulating blanket over terminals 247 and 248 (120 vac) 


$$
\begin{aligned}
& \text { HNF-SD-C189-ATP-001 } \\
& \text { Rev. } \not 0
\end{aligned}
$$

DQe Install a jumper between terminals 213 and 203 in Generator -. 1 switchgear cubicle and verify the following

Dou LOW BATTERY VOLTAGE lamp for generator 1 is illuminated.

Q6) Verify the alarm horn in 2721-Z sounds.

Qu Press the horn silence button on the switchgear master section and verify the horn is silenced.

DW Verify a DCS EAL_GENI alarm was received.

DW Remove jumper between terminals 213 and 203.

QW Remove insulating blanket over terminals 247 and 248 (120 vac)

\subsubsection{Breaker Position}

DOQ 0 Turn generator 1 mode switch to the MANUAL position and verify that the generator starts.

Dow Verify the DCS generator status display shows generator 1 in manual mode and a DCS event is printed.

Dow Turn breaker control handle for generator 1 and verify breaker CLOSES.

DOW Verify the GEN 1 ON LINE light illuminates on the switchgear master section.

ODW Verify the DCS generator status display shows generator 1 in manual and generator 1 breaker closed.

2.5.3 High Water Temperature

ODW Insta11 a jumper between terminals 206 and 203 in Generator 1 switchgear cubicle and verify the following:

DQde HIGH WATER TEMP lamp for generator 1 is illuminated.

DU GEN 1 TROUBLE lamp for generator 1 is 1 lluminated on the switchgear master section.

Dow Verify the alarm horn in 2721-Z sounds.

DW Press the horn silence button on the switchgear master section and verify the horn is silenced.

DOQ Verify a OCS TAH_GENI alarm was received.

DOW Verify generator 1 engine stops and generator 1 breaker OPENS. 


$$
\begin{gathered}
\text { HNF-SD-C189-ATṔ-001 } \\
\text { Rev. } x_{0}
\end{gathered}
$$

OQd Remove jumper between terminals 206 and 203.

Qlu Turn generator mode switch to OFF/RESET to reset controller.

De) 2.5.4 Return generator 1 mode switch to the MANUAL position and verify that the generator restarts.

$\frac{0}{260}$

\subsubsection{Low 0it Pressure}

OOW Install a jumper between terminals 204 and 203 in Generator 1 switchgear cubicle and verify the following:

DOS LOW OIL. PRESSURE lamp for generator I is illuminated.

OOW GEN 1 TROUBLE 1 amp for generator 1 is 117 uminated on the switchgear master section.

Q0 Verify the al arm horn in $2721-Z$ sounds.

Du Press the horn silence button on the switchgear master section and verify the horn is silenced.

OQW Verify a DCS PAL GENI alarm was received.

DOW Verify the engine stops.

Dle Remove jumper between terminals 204 and 203.

DOW Turn generator mode switch to OFF/RESET to reset controller.

Qls 2.5.6 Return generator I mode switch to the MANUAL position and verify that the generator restarts.

Doe 2.5.7 Engine Overspeed 8.269

DW OPEN field breaker in generator control cabinet (located in lower right).

QW Have Mechanic manually override governor to increase speed until engine stops and verify the following:

QD OVERSPEED 7 amp for generator 1 is illuminated.

DQD GEN 1 TROUBLE lamp for generator 1 is $i 1$ uminated on the switchgear master section.

DD Verify the aiarm horn in $2721-2$ sounds.

Dow Press the horn silence button on the switchgear master section and verify the horn is silenced.

DDW Verify a DCS SAH_GEN1 alarm was received. 


$$
\begin{gathered}
R \\
\text { HNF-SD-C189-AT } p-001 \\
\text { Rev. } y O
\end{gathered}
$$

DOW CLOSE field breaker in generator control cabinet (located in.. lower right).

Dow Turn generator mode switch to OFF/RESET to reset controller.

DOU Return generator 1 mode switch to the AUTO position.

\subsubsection{OVER CRANK (start fail)}

Dev Install insulating blanket over terminals 247 and 248 (120 vac)

ONe Install a jumper between terminals 235 and 236 in Generator 1 switchgear cubicle and verify the following:

QUUV Verify a DCS XA_GI_1 al arm was received.

DQ0 Remove jumper between terminals 235 and 236 .

DW Remove insulating blanket over terminals 247 and 248 (120 vac)

Dow 2.5.9 Control Power Failure 9.2697

Dow Turn off control power for generator I by turning off circuit breaker $1-C B$ in the lower right of generator 1 switchgear cubicle.

DOW Verify GEN I TROUBLE 1 amp for generator 1 is $i l l$ uminated on the switchgear master section.

Dow Verify on the DCS values table that the 1-CPR input is on.

ONe) Turn on control power for generator 1 by turning on circuit breaker 1-CB in the lower right of generator 1 switchgear cubicle.

Ooli 2.5.10 Generator Shutdown Relay

OOW Verify the generator mode switch is in the AUTO position.

DQ6 Press the Emergency Stop switch for generator 1.

OOb Verify GEN I TROUBLE lamp for generator 1 is illuminated on the switchgear master section.

Dow Verify on the DCS values table that the 1-SDR input is on.

Now Verify the alarm horn in 2721-Z sounds:

Dow Press the horn silence button on the switchgear master section and verify the horn is silenced. 


$$
\begin{gathered}
R^{R} \\
\text { HNF-SD-C189-ATP-001 } \\
\text { Rev. } y 0
\end{gathered}
$$

ONo Release the Emergency Stop switch for generator 1.

QDeD Turn generator mode switch to OFF/RESET to reset controller.

DOW Return generator I mode switch to the AUTO position.

\section{Des 2.6 Generator 2 Controls and Alarms}

2.6.1 Low Battery Voltage

Dow Install insulating blanket over terminals 447 and 448 (120 vac)

QWe Install a jumper between terminals 413 and 403 in Generator 2 switchgear cubicle and verify the following

DOW LOH BATTERY VOLTAGE 1 amp for generator 2 is illuminated.

Do Verify the alarm horn in 2721-2 sounds.

- Do Press the horn silence button on the switchgear master section and verify the horn is silenced.

ODW Verify a DCS EAL_GEN2 alarm was received.

DW Remove jumper between terminals 413 and 403 .

OQN Remove insulating blanket over terminals 447 and 448 (120 vac)

\section{Dow 2.6.2 Breaker Position}

\subsection{6 .9}

DOWTurn generator 2 mode switch to the MANUAL position and verify that the generator starts.

Dow Verify the DCS generator status display shows generator 2 in manual mode and a DCS event is printed.

QQN Turn breaker control handle for generator 2 and verify breaker CLOSES.

Dow Verify the GEN 2 ON LINE light illuminates on the switchgear master section.

Dow Verify the DCS generator status display shows generator 2 in manual and generator 2 breaker closed.

Dow) 2.6.3 High Water Temperature $826-9$

Dow Install a jumper between terminals 406 and 403 in Generator 2 switchgear cubicle and verify the following:

Dow HIGH WATER TEMP lamp for generator 2 is illuminated. 


$$
\begin{gathered}
\text { HNF-SD-C189-AT }{ }^{R}-001 \\
\text { ReV. } Y_{0}
\end{gathered}
$$

D) GEN 2 TROUBLE 1 amp for generator 2 is illuminated on .. the switchgear master section.

DQ Verify the alarm horn in $2721-z$ sounds.

Dow Press the horn silence button on the switchgear master section and verify the horn is silenced.

DQ Verify a OCS TAH_GEN2 al arm was received.

Dus Verify generator 2 engine stops and generator 2 breaker OPENS.

DQ0 Remove jumper between terminals 406 and 403.

DOW Turn generator mode switch to OFF/RESET to reset controller.

OQW 2.6.4 Return generator 2 mode switch to the MANUAL position and verify that the generator restarts.

Dov 2.6.5 Low 0il Pressure

Dow Install a jumper between terminals 404 and 403 in Generator 2 switchgear cubicle and verify the following:

DU LOH OIL PRESSURE 1 amp for generator 2 is illuminated.

DOW GEN 2 TROUBLE lamp for generator 2 is illuminated on the switchgear master section.

DOW Verify the alarm horn in 2721-Z. sounds.

PNe Press the horn silence button on the switchgear master section and verify the horn is silenced.

OQW Verify a DCS PAL_GEN2 alarm was received.

OOW Verify the engine stops.

Q0w Remove jumper between terminals 404 and 403 .

QOW Turn generator mode switch to OFF/RESET to reset controller.

DON 2.6.6 Return generator 2 mode switch to the MANUAL position and verify that the generator restarts.

\subsubsection{Engine Overspeed}

OOD OPEN field breaker in generator control cabinet (located in 8.26 .97 lower right). 


$$
\begin{gathered}
R \\
\text { HNF-SD-C189-ATṔ-001 } \\
\text { Rev. Yo }
\end{gathered}
$$

Dow Have Mechanic manually. override governor to increase speed .. 82691 until engine stops and verify the following:

Qo OVERSPEED 1 amp for generator 2 is 11 luminated.

DDS GEN 2 TROUBLE lamp for generator 2 is illuminated on the switchgear master section.

QD Verify the alarm horn in $2721-z$ sounds.

Dow Press the horn silence button on the switchgear master section and verify the horn is silenced.

DUW Verify a DCS SAH_GEN2 a] arm. was received.

OQD CLOSE field breaker in generator control cabinet (located in lower right).

DW Turn generator mode switch to OFF/RESET to reset controller.

now Return generator 2 mode switch to the AUTO position.

QDe 2.6 .8 OVER CRANK (start fail)

$8.26-97$

QOW Instal? insulating blanket over terminals 447 and 448 (120 vac)

OW Install a jumper between terminals 435 and 436 in Generator 2 switchgear cubicle and verify the following:

OOW Verify a OCS XA_G2_1 al arm was received.

SOW Remove jumper between terminals 435 and 436 .

OOU Remove insulating blanket over terminals 447 and 448 (120 vac)

$\frac{000}{8-269}$

2.6.9 Control Power Failure

Dow Turn off control power for generator 2 by turning off circuit breaker 2-CB in the lower right of generator 2 switchgear cubicle.

DW Verify GEN 2 TROUBLE lamp for generator 2 is illuminated on the switchgear master section.

DOW Verify on the DCS values table that the 2-CPR input is on.

Sow Turn on control power for generator 2 by turning on circuit breaker $2-C B$ in the lower right of generator 2 switchgear cubicie. 


$$
\begin{gathered}
\text { HNF-SD-C189-ATP-001 } \\
\text { Rev. } \not>0
\end{gathered}
$$

Dow 2.6.10 Generator Shutdown Relay 8.2697

QW Verify the generator mode switch is in the AUT0 position.

NOW Press the Emergency Stop switch for generator 2.

DOW Verify GEN 2 TROUBLE Tamp for generator 2 is illuminated on the switchgear master section.

DQu Verify on the DCS values table that the 2-SDR input is on.

DQ Verify the alarm horn in 2721-Z sounds.

OW Press the horn silence button on the switchgear master section and verify the horn is silenced.

DOW Release the Emergency Stop switch for generator 2.

PDe Turn generator mode switch to OFF/RESET to reset controller.

SQe Return generator 2 mode switch to the AUTO position.

ONo 2.7 Generator 3 Controls and Alarms

ODW 2.7.1 Low Battery Voltage $8-\partial(0)$

Dow Install insulating blanket over terminals 647 and 648 (120 vac)

DQD Install a jumper between terminals 613 and 603 in Generator 3 switchgear cubicle and verify the following

DOW LOW BATTERY VOLTAGE lamp for generator 3 is illuminated.

Do Verify the alarm horn in $2721-z$ sounds.

DQ Press the horn silence button on the switchgear master section and verify the horn is silenced.

DOW Verify a DCS EAL_GEN3 a larm was received.

SOW Remove jumper between terminais 613 and 603 .

DQW Remove insulating blanket over terminals 647 and 648 (120 vac)

\section{Oow 2.7.2 Breaker Position}

8.2697

QDWTurn generator 3 mode switch to the MANUAL position and verify that the generator starts.

Dow Verify the DCS generator status display shows generator 3 in manual mode and a DCS event is printed. 



$$
\begin{gathered}
\text { HNF-SD-C189-ATR } \\
\text { Rev. } X_{0}^{R}-001
\end{gathered}
$$

Dow Verify the engine stops.

Dov Remove jumper between terminals 604 and 603 .

Dow Turn generator mode switch to OFF/RESET to reset controller.

Sio 2.7 .6 Return generator 3 mode switch to the MANUAL position and verify that the generator restarts.

8.2600

\subsubsection{Engine Overspeed}

Dow OPEN field breaker in generator control cabinet (located in lower right).

Dow Have Mechanic manually override governor to increase speed until engine stops and verify the following:

DQW OVERSPEED lamp for generator 3 is 117 uminated.

DOW GEN 3 TROUBLE lamp for generator 3 is $i l l$ uminated on the switchgear master section.

Oow Verify the alarm horn in 2721-Z sounds.

Do Press the horn silence button on the switchgear master section and verify the horn is silenced.

DOW Verify a DCS SAH_GEN3 al arm was received.

OQ CLOSE field breaker in generator control cabinet (located in lower right).

Dow Turn generator mode switch to OFF/RESET to reset controlier.

DOW Return generator 3 mode switch to the AUTO position.

$\frac{0(2)}{8269}$

\subsubsection{OVER CRANK (start fai])}

OOW Install insulating blanket over terminals 647 and 648 (120 vac)

Dow Install a jumper between terminals 635 and 636 in Generator 3 switchgear cubicle and verify the following:

Dow Verify a DCS XA_G3_1 al arm was received.

Dow Remove jumper between terminals 635 and 636 .

POW Remove insulating blanket over terminals 647 and 648 (120 vac) 


\section{Dow 2.7.9 Control Power Failure $82(69)$ \\ Qole Turn off control power for generator 3 by turning off circuit breaker $3-C B$ in the lower right of generator 3 switchgear cubic\}e. \\ ODW Verify GEN 3 TROUBLE lamp for generator 3 is illuminated on the switchgear master section. \\ POW verify on the DCS values table that the 3-CPR input is on. \\ Ox Turn on control power for generator 3 by turning on circuit breaker 3-CB in the lower right of generator 3 switchgear cubicle. \\ DOW 2.7.10 Generator Shutdown Relay 8209 \\ DOL Verify the generator mode switch is in the AUTO position. \\ Dow Press the Emergency Stop switch for generator 3 . \\ DOW Verify GEN 3 TROUBLE lamp for generator 3 is illuminated on the switchgear master section. \\ Des, Verify on the. DCS values table that the 3-SDR input is on. \\ Q10 Verify the alarm horn in $2721-Z$ sounds. \\ Dow Press the horn silence button on the switchgear master section and verify the horn is silenced. \\ ODe Release the Emergency Stop switch for generator 3 . \\ DOe Turn generator mode switch to OFF/RESET to reset controller. OOW Return generator 3 mode switch to the AUTO position.}

DOU 2.8 Miscellaneous Inputs and Outputs बिर्जा

OD. $2.8,1$ Test Switches

DOW Turn generator mode switches for generators 1,2 and 3 to OFF/RESET position.

DU Turn and hold the Test Switch on the Switchgear Master section to the LOAD position.

OWerify on the DCS values table that the LOAD TEST input is on.

Dow Turn and hold the Test Switch on the Switchgear Master section to the SYSTEM position. 


$$
\begin{gathered}
\text { HNF-SO-C189-ATP-001 } \\
\text { Rev. Yo }
\end{gathered}
$$

ONe Verify on the DCS values table that the SYSTEM TEST input is.on.

DQD Release the Test Switch on the Switchgear Master section.

DDN Press and hold the EGS Test Emergency Stop Switch on the Switchgear Master section.

DL Verify on the DCS values table that the EGS Test Emergency Stop input is on.

Dete Release the EGS Test Emergency Stop Switch on the Switchgear Master section.

De Turn generator mode switches for generators 1,2 and 3 to AUTO position.

Ores 2.8.2 Automatic Generator Load Controller (AGLC) 8.229

\subsubsection{Base Load Signal}

QDe Install insulating blanket over $120 \mathrm{vac}$ terminals of AGLC.

DOW Install a VOM on terminals 11 and 12 of the Woodward AGLC in the Master Switchgear section.

WNe Verify the $D C$ voltage reading across terminals is between -0.05 volts to +0.05 volts.

OOW Request DCS Operator to use the AGLC controller to increase the AGLC output to maximum.

D. Verify the $D C$ voltage reading across terminals is between 2.95 volts to 3.05 volts.

DOW Request DCS Operator to use the AGLC controller to decrease the AGLC output to minimum.

DOW Remove insulating blanket over 120 vac terminals of AGLC.

\subsubsection{AGLC and VAR/PF Controllers}

OQW Wiring for the AGLC and VAR/PF controllers using ECNs C189043, Cl89-046 and C189-038 was verified in work package 962749.

AGLC and VAR/PF Controllers are correctly installed and ready for operational testing

*

Power systems Representative ${ }^{\prime} \overline{\text { Date }}$

* Ser following page do-A, Reu o for. power systems Reprasentative signature. 


$$
\begin{gathered}
\text { HNF-SD-C189-ATP'-001 } \\
\text { ReV. } 0
\end{gathered}
$$

\subsubsection{AGLC and VAR/PF Controllers}

Wiring for the AGLC and VAR/PF controllers using ECNS C189012 and $\mathrm{C} 189-038$ was verified in work package 96-2749.

AGLC and VAR/PF Controllers are correctly installed and ready for operational testing

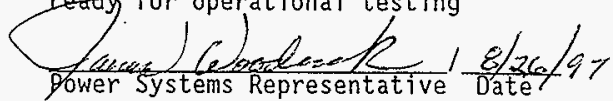

\subsubsection{Signals from 234-5Z Transfer Control Panel}

\subsubsection{Normal Bus Over/Under Frequency}

On the DCS Values table verify the 234-5Z Normal Bus Over/Under Frequency input is $O N$.

Lift wire 1604 or 34-1604 from terminal in CTBX-1.

On the DCS Values table verify the 234-5Z Normal Bus

Overyunder Frequency input is OFF.

Land wike 1604 or 34-1604 lifted in CTBX-1 in previous step.

On the DCS Values table verify the 234-5Z Normal Bus

Over/Under Axequency input is $0 N$.

\subsubsection{Normal Bus Oker/Under Voltage}

On the DCs values table verify the 234-5Z Normal Bus Over/Under Voltage ikput is ON.

Lift wire 1605 or 34-165 from terminal in CTBX-1.

On the DCS Values table verfy the 234-5Z Normal Bus Over/Under Voltage input is QF.

Land wire 1605 or 34-1605 lifted in CTBX-1 in previous step.

On the DCS Values table verify the 234-5Z Normal Bus

Over/Under voltage input is oN.

\subsubsection{3 $\cdot 234-5 Z$ Emergency Bus Over/Under Frequency}

On the DCS Values table verify the 234-5Z Energency Bus Over/Under Frequency input is $0 N$.

Lift wire 1606 or 34-1606 from terminal in CTBX-X.

On the DCS Values table verify the $234-5 Z$ Over/Under Frequency input is OFF. 
$R$

HNF-SO-C189-ATP-001

Rev. $\lambda_{0}$

ON 2.8.3 Signals from 234-52 Transfer Control Panel

$9-2697$

2.8.3.1 Normal Bus Over/Under Frequency

Q2 On the DCS Values table verify the 234-5Z Normal Bus

Over/Under Frequency input is OFF.

OQD Jumper wires 1604 and 34-1604 in generator switchgear master section.

QQe on the DCS Values table verify the 234-5Z Normal Bus over/Under Frequency input is $0 \mathrm{~N}$.

D. Remove jumper from 1604 and 34-1604 in generator switchgear master section.

De On the OCS Values table verify the 234-5Z Normal Bus Over/Under Frequency input is OFF.

2.8.3.2 Normal Bus Over/Under Voltage

QDe on the DCS Values table verify the 234-5Z Normal Bus over/Under Voltage input is OFF.

Dod Jumper wires 1605 and 34-1605 in generator switchgear master section.

Q00 on the DCS Values table verify the 234-5Z Normal Bus Over/Under Voltage input is ON.

SOQ Remove jumper from 1605 and 34-1605 in generator switchgear master section.

Dow on the DCS values table verify the 234-5Z Normal Bus Over/Under Voltage input is OFF.

\subsubsection{234-5Z Emergency Bus Over/Under Frequency}

Nod On the DCS Values table verify the 234-5Z Emergency Bus Over/Under Frequency input is $0 N$.

QOu Lift wire 1606 or 34-1606 from terminal in generator switchgear master section.

Q0 On the DCS Values table verify the 234-5Z Emergency Bus Over/Under Frequency input is OFF.

Dole Land wire 1606 or 34-1606 lifted in generator switchgear master section in previous step.

Dow Jon the DCS Values table verify the 234-5Z Emergency Bus over/Under Frequency input is ON. 


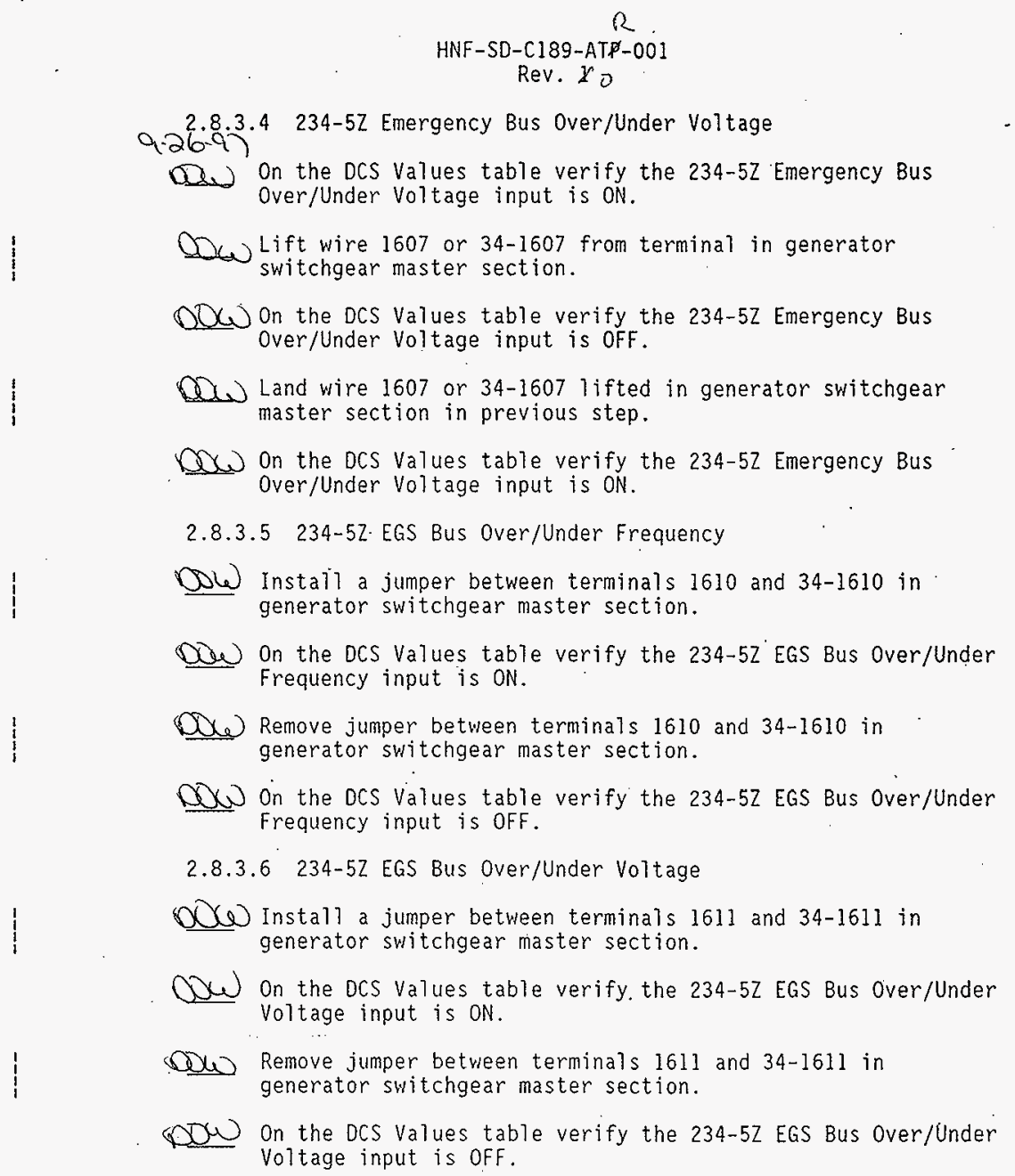




$$
\begin{gathered}
\text { HNF-SD-C189-AT\$-001 } \\
\text { Rev. }{ }_{0}^{2}
\end{gathered}
$$

Dus

2.8.4 234-5Z Breaker Position Indications

\subsubsection{F8X309}

\section{WARNING}

Electrical SHOCK potential is present (480 \& $120 \mathrm{VAC}, 125 \mathrm{VDC})$ on in the compartment while installing and removing jumpers. Install insulating. blanket over terminals and equipment adjacent to terminal being tested.

PERSONAL INUURY COULD OCCUR.

\section{REFER TO WHC-CM-1-10}

OW Install a jumper between terminals QCF (F8 \& 1513) AND QCG $8-22.9$ ) (F9 \& 34-1513) in section 15 top compartment Room 266 switchgear.

OQ Verify F $8 \times 309$ is shown as CLOSED on the DCS Generator display.

DU. Remove jumper between terminals QCF (F8 \& 1513) AND QCG (F9 \& 34-1513) in section 15 top compartment Room 266 switchgear.

DON Install a jumper between terminals QCH (F3 \& 1514) AND QCJ (F4 \& 34-1514) in section 15 top compartment Room 266 switchgear.

Now Verify F $8 \times 309$ is shown as OPEN on the DCS Generator display.

DOS Remove jumper between terminals QCH (F3 \& 1514) AND QCJ (F4 \& 34-1514) in section 15 top compartment Room 266 switchgear.

\section{$2.8 .4 .2 \quad F 8 \times 400$}

\section{WARNING}

Electrical SHOCK potential is present (480 \& $120 \mathrm{VAC}, 125 \mathrm{VDC})$ on in the compartment while installing and removing jumpers. Install insulating blanket over terminals and equipment adjacent to terminal being tested.

PERSONAL INJURY COULO OCCUR.

REFER TO WHC-CM-1-10

DONverify $F 8 \times 400$ is shown as OPEN on the DCS Generator display. 
$R$

HNF-SD-C189-ATP-001

Rev. 10

Dow In section 15 top compartment Room 266 switchgear, lift wire.E2 (34-1602) or E1 (1602) and install jumper between wires E6 (34-1601) and E5 (1601).

DOWVerify F $8 \times 400$ is shown as CLOSED on the DCS Generator display.

Q0D In section 15 top compartment Room 266 switchgear, land wire E2 (34-1602) or E1 (1602) and remove jumper between wires E6 $(34-1601)$ and $E 5(1601)$.

DOW Verify F8X400 is shown as OPEN on the DCS Generator display.

\subsubsection{3 $\quad F 8 \times 340$}

\section{WARNING}

Electrical SHOCK potential is present (480 \& $120 \mathrm{VAC}, 125 \mathrm{VDC}$ ) on in the compartment while installing and removing jumpers. Install insulating blanket over terminals and equipment adjacent to terminal being tested.

PERSONAL INJURY COULD OCCUR.

REFER TO WHC-CM-1-10

De.) Verify F8X340 is shown as CLOSED on the DCS Generator 8.22 .97 display.

DQw In section 15 top compartment Room 266 switchgear, lift wire T6 (34-1515A) or T5 (1515) and install jumper between wires T2 $(34-1516)$ and $T 1(1516)$.

DOW Verify F8X340 is shown as OPEN on the DCS Generator display.

Des In 2721-2 Switchgear Master section, land wire 34-1515 or 1515 lifted in earlier step and remove jumper between wires $34-1516$ and 1516 .

OD.) Verify F $8 \times 340$ is shown as CLOSED on the OCS Generator display.

DQW 2.8.5 Generator Bus Load Circuit Breaker Position/Control 8.26 .97

2.8.5.I Set-up

POW Turn mode switches for generators 1,2 and 3 to the OFF/RESET position

\subsubsection{272]-Z CBI}

QWWiring for 2721-Z CB1 breaker control using ECN's C189-043 and $[-189-046$ was verified in work package 96-2749. 
QOW Verify $2721-Z$ CBI is shown as OPEN on the DCS Generator 8.269 display.

DOW Remove energy control from CBI and CLOSE.

DOW Verify 2721-Z CBI is shown as CLOSED on the DCS Generator display.

OU OPEN CBI and install energy control..

$2.8 .5 .3 \quad 2721-Z$ CB2

DOW Verify $2721-Z$ CB2 is shown as OPEN on the DCS Generator display.

ONU CLOSE CB2.

DOW Verify $2721-Z$ CB2 is shown as CLOSED on the DCS Generator display.

DON OPEN CB2.

$2.8 \cdot 5 \cdot 4 \quad 2721-2$ CB3

$8.22 .9)$

OOW Verify $2721-Z$ CB3 is shown as OPEN on the DCS Generator display.

OOU) CLOSE. CB3.

OON Verify $2721-Z$ CB3 is shown as CLOSED on the DCS Generator display.

OOM OPEN CB3.

$2.8 .5 .5 \quad 2721-7 \quad$ CB4

$0.22 .9)$

OW Verify $2721-Z$ CB4 is shown as OPEN on the DCS Generator display.

DOW CLOSE CBA.

ON Verify 2721-Z CBA is shown as CLOSEO on the DCS Generator display.

DQu OPEN CBA.

QDW 2.8.6 Panel NP-VF-1-3 (CB 3) Position Indication and Control. 8.2297

DOW Wiring for NP-VF-1-3 in accordance with ECN's C189-043 and C189-046 was verified in work package 96-2749.

OQW Verify NP-VF-1-3 is shown as CLOSED on the DCS generator display. 


$$
\begin{gathered}
R \\
\text { HNF-SD-C189-ATṔ-001 } \\
\text { Rev. } \neq 0
\end{gathered}
$$

ONo 2.8.7 ATS position indications 2.22 .91

\subsubsection{ATS-2}

OOW Verify ATS-2 is shown in the NORMAL position on the DCS Generator display.

DOw Lift either 1507 or 34-1507 in CBTX-1 in 2721-Z.

POW Verify ATS-2 is shown in the intermediate position on the DCS Generator display.

Do. Install a jumper between 1508 and 34-1508 in generator switchgear master section in 2721-Z.

OSe Verify ATS-2 is shown in the EGS position on the DCS Generator display.

Oow Remove jumper between 1508 and $34-1508$ in generator switchgear master section in 2721-z.

Oob Land either 1507 or 34-1507 lifted in earlier step in CBTX-1 in $2721-2$.

DOW Verify ATS-2 is shown in the NORMAL position on the DCS Generator display.

2.8 .7 .2 ATS -3

8.22 .97

DOW Verify ATS-3 is shown in the MORMAL position on the DCS Generator display.

Dis Lift either 1509 or 34-1509 in CBTX-1 in 2721-Z.

Daw Verify ATS -3 is shown in the intermediate position on the DCS Generator display.

QD Install a jumper between 1510 and $34-1510$ in CBTX-1 in $2721-2$.

DD. Verify ATS-3 is shown in the EGS position on the DCS Generator display.

Dod Remove jumper between 1510 and $34-1510$ in CBTX-1 in 2721-Z. DOW Land either 1509 or $34-1509$ lifted in earlier step in CBTX-1
in 2721-2.

DOW Verify ATS-3 is shown in the NORMAL position on the DCS Generator display. 


$$
\begin{gathered}
\text { HNF-SD-C189-ATṔ-001 } \\
\text { Rev. } X_{0}
\end{gathered}
$$

2.8.7.3 ATS -4

8.2297

DOW Verify ATS-4 is shown in the NORMAL position on the DCS Generator display.

Dow lift either 1511 or 34-1511 in CBTX-1 in 2721-2.

DOW Verify ATS-4 is shown in the intermediate position on the DCS Generator display.

DOW Insta11 a jumper between 1512 and $34-1512$ in CBTX-1 in $2721-Z$.

DOD Verify ATS-4 is shown in the EGS position on the DCS Generator display.

DOw Remove jumper between 1512 and 34-1512 in CBTX-1 in 2721-Z.

OOW Land either 1511 or 34-1511 lifted in earlier step in. CBTX-1 in 2721-Z.

OOW Verify ATS 4 is shown in the NORMAL position on the DCS Generator display.

Dow 2.8.8 Over/Under Voltage/Frequency and Reset 8.26097

DOW Verify the OVER/UNDER VOLTAGE and OVER/UNDER FREQUENCY inputs are OFF using the DCS Values table.

DW Start one generator by moving the mode switch to the MANUAL position.

Dow CLOSE the circuit breaker for the operating generator.

POW Verify the OVER/UNDER VOLTAGE and OVER/UNDER FREQUENCY inputs are ON using the DCS Values table.

DND Press the O/U VOLT FREQ. RESET on the Switchgear Master section.

OND Momentarily (more than 2 seconds) disconnect wire 61 on TB11 in the switchgear master section (O/U FREQ).

DOW Verify the O/U FREQ light is illuminated.

Dow Verify the alarm horn in $2721-z$ sounds.

Row Press the horn silence button on the switchgear master section and verify the horn is silenced.

OOW press the O/U VOLT FREQ. RESET on the Switchgear Master section. 


$$
\begin{gathered}
R \\
\text { HNF-SD-C189-ATP-001 } \\
\text { Rev. } \alpha_{0}
\end{gathered}
$$

De Verify the 0/U FREQ light is extinguished.

DOW Ostop operating generator by moving the mode switch to the AUTO position.

DOW 2.8.9 2721-Z UPS Failure 82297

DOW Unplug the power supply cord to the 2721-Z UPS.

DOW Verify a DCS UPS_GEN alarm was received.

D) DPlug the power supply cord for the 2721-Z UPS back in. 


$$
\begin{gathered}
\text { HNF-SD-CI89-ATP'-001 } \\
\text { Rev. } 10
\end{gathered}
$$

OQD2.9 Transducer Inputs

\begin{tabular}{|c|c|c|c|c|c|}
\hline Transducer & Connection Point & Test VaTue & DCS Value & Actual DCS & Verified \\
\hline \multicolumn{6}{|c|}{ Generator I Watt } \\
\hline Range $0-1$ madc & & 0 madc & $0 \mathrm{kw}$ to $20 \mathrm{kw}$ & .5 & 004 \\
\hline Scale $0-400 \mathrm{KW}$ & $1-X D C R$ & $1 \mathrm{madc}$ & $360 \mathrm{kw}$ to $440 \mathrm{kw}$ & 400 & oow \\
\hline \multicolumn{6}{|c|}{ Generator 1 VAR } \\
\hline Range $0-1$ madc & & 0 madc & 0 kvar to 20 kvar & 1.0 & Dou \\
\hline Scale $0-400$ KVAR & $1-x O C R$ & $1 \mathrm{madc}$ & 360 kvar to 440 kvar & 413.8 & ODW \\
\hline \multicolumn{6}{|c|}{ Generator 2 Watt } \\
\hline Range $0-1 \mathrm{madc}$ & & 0 madc & $0 \mathrm{kw}$ to $20 \mathrm{kw}$ & 0 & DOM \\
\hline Scale $0-400 \mathrm{KW}$ & $2-\times D C R$ & 1 madc & $360 \mathrm{kw}$ to $440 \mathrm{kw}$ & 400 & oOn \\
\hline \multicolumn{6}{|c|}{ Generator 2 VAR } \\
\hline Ranqe $0-1$ madc & & 0 madc & 0 kvar to 20 kvar & .6 & Dous \\
\hline Scale $0-400$ KVAR & $2-\times D C R$ & $1 \mathrm{madc}$ & 360 kvar to 440 kvar & 400 & OON \\
\hline \multicolumn{6}{|c|}{ Generator 3 Watt } \\
\hline Range $0-1$ madc & & 0 madc & $0 \mathrm{kw}$ to $20 \mathrm{kw}$ & 1.0 & 000 \\
\hline Scale $0-400 \mathrm{KW}$ & $3=\times D C R$ & $1 \mathrm{madc}$ & $360 \mathrm{kw}$ to $440 \mathrm{kw}$ & 399 & $00(0)$ \\
\hline
\end{tabular}

Verify the following transducer inputs on the DCS values table. For each transducer, record the test connection point and the results of the minimum and maximum range test points. 
Rev. $\Lambda_{0}$

\begin{tabular}{|c|c|c|c|c|c|}
\hline Transducer & Connection Point & Test Value & DCS value & Actual DCS & Verified \\
\hline \multicolumn{6}{|c|}{ Generator 3 VAR } \\
\hline Range $0-1$ madc & & 0 madc & 0 kvar to 20 kvar & 1.0 & OOM \\
\hline Scale $0-400$ KVAR & $3-X O C R$ & $1 \mathrm{madc}$ & 360 kvar to 440 kvar & 401 & Dou \\
\hline \multicolumn{6}{|c|}{ Generator Bus Load Breaker I Phase A Current } \\
\hline Range $0-5$ amps & $\begin{array}{l}7 T \text { CBI-A } \\
\text { Ierms: }+33\end{array}$ & 0 amps & 0 amps to 20 amps & -.6 & Dow \\
\hline Scale $0-400$ amps & 4.8 & 5 amps & 360 amps to 440 amps & 390 & Don \\
\hline \multicolumn{6}{|c|}{ Generator Bus Load Breaker I Phase B Current } \\
\hline Range $0-5$ amps & $\begin{array}{l}\text { ISCBI-B } \\
\text { Ferms } 1+3\end{array}$ & 0 amps & 0 amps to 20 amps & .0 & OON \\
\hline Scate $0-400$ amps & 4.8 & 5 amps & 360 amps to 440 amps & 390 & $\mathrm{OON}$ \\
\hline \multicolumn{6}{|c|}{ Generator Bus Load Breaker I Phase C Current } \\
\hline Range $0-5$ anas & $\begin{array}{l}\text { IT-CBI-C } \\
\text { Terms } 1+3\end{array}$ & 0 amps & 0 amps to 20 amps & 0,1 & ON \\
\hline Scale $0-400$ amps & 4.7 & 5 amps & 360 amps to 440 amps & 385 & $00 \times$ \\
\hline \multicolumn{6}{|c|}{ Generator Bus Load Breaker 2 Phase A Current } \\
\hline Range $0-5$ amps & $\begin{array}{l}\text { IT. CBO } 2-\mathrm{A}_{3} \\
\text { Tarms }+3\end{array}$ & 0 amps & 0 amps to 20 amps & .2 & 000 \\
\hline Scale 0.400 amps & 5.0 & 5 amps & 360 amps to 440 amps & 415 & DOW \\
\hline \multicolumn{6}{|c|}{ Generator Bus Load Breaker 2 Phase B Current } \\
\hline Range 0.5 amps & $\begin{array}{l}7 . c 02-3 \\
\text { Terms }+3 \\
\end{array}$ & 0 amps & 0 amps to 20 amps & $Q$ & Dow \\
\hline Scale $0-400$ amps & 4,5 & 5 amps & 360 amps to 440 amps & 3) 2 & Dou \\
\hline
\end{tabular}

8.28 .97 
HNF-SD-C189-ATD-001

Rev. ho

\begin{tabular}{|c|c|c|c|c|c|}
\hline Transducer & Connection Point & Test Vaiue & DCS value & Actual DCS & Verified \\
\hline \multicolumn{6}{|c|}{ Generator Bus Load Breaker 2 Phase $C$ Current } \\
\hline Range $0-5$ amps & Farma $1 \mathrm{Cl}^{2} 3$ & 0 amps & 0 amps to 20 amps & .03 & Dow \\
\hline Scale $0-400$ amps & 5.0 & 5 amps & 360 amps to 440 amps & 405 & Dow \\
\hline \multicolumn{6}{|c|}{ Generator Bus Load Breaker 3 Phase A Current } \\
\hline Range $0-5$ amps & $\begin{array}{l}\text { It-cr33.A } \\
\text { aerms }\end{array}$ & 0 amps & 0 amps to 20 amps & 2 & Dow \\
\hline Scale $0-400$ amps & 4.8 & 5 amps & 360 amps to 440 amps & 396 & Dow \\
\hline \multicolumn{6}{|c|}{ Generator Bus Load Breaker 3 Phase B Current } \\
\hline Range $0-5$ amps & $\begin{array}{l}-5 x-\cos 3-18 \\
\text { reins }+3\end{array}$ & 0 amps & 0 amps to 20 amps & 0 & oon \\
\hline Scale $0-400$ amps & 5 & 5 amps & 360 amps to 440 amps & 409 & Dou \\
\hline \multicolumn{6}{|c|}{ Generator Bus Load Breaker 3 Phase C Current } \\
\hline Range $0-5$ amps & $\begin{array}{l}F T-\cos 3-c \\
\text { Terms } 1+3\end{array}$ & 0 amps & 0 amps to 20 amps & .08 & 000 \\
\hline Scale $0-400$ amps & 4,6 & 5 amps & 360 amps to 440 amps & 3) 9 & 004 \\
\hline \multicolumn{6}{|c|}{ Generator Bus Load Breaker 4 Phase A Current } \\
\hline Range $0-5$ amps & $\begin{array}{l}\text { AT-CB }-A \text { - } \\
\text { Term ix }\end{array}$ & 0 amps & 0 amps to 20 amps & 0.2 & Dow \\
\hline Scale $0-400$ amps & 4.8 & 5 amps & 360 amps to 440 amps & 390 & Dow \\
\hline \multicolumn{6}{|c|}{ Generator Bus Load Breaker 4 Phase B Current } \\
\hline Range $0-5$ amps & $\begin{array}{l}37-\cos 4-3 \\
\text { ferms } 1+3\end{array}$ & 0 amps & 0 amps to 20 amps & 0 & Dow \\
\hline Scale $0-400$ amps & 4.7 & 5 amps & 360 amps to 440 amps & 324 & pow \\
\hline
\end{tabular}




\begin{tabular}{|c|c|c|c|c|c|}
\hline Transducer & Connection Point & Test value & DCS value & Actual DCS & Verified \\
\hline \multicolumn{6}{|c|}{ Generator Bus Load Breaker 4 Phase C Current } \\
\hline Range $0-5$ amps & $\frac{7 T-c B 4-C}{143}$ & 0 amps & 0 amps to 20 amps & 0 & Nones \\
\hline Scale $0-400$ amps & 4.5 & 5 amps. & 360 amps to 440 amps & 360 & DOW \\
\hline \multicolumn{6}{|c|}{ Generator Bus Voltage Phase A } \\
\hline $\begin{array}{l}\text { Range } 0-150 \\
\text { volts }\end{array}$ & $E T-E G S-A$ & 0 volts & 0 volts to 6 volts & 0 & 0020 \\
\hline $\begin{array}{l}\text { Scale } 0-600 \\
\text { volts }\end{array}$ & & 120 volts & $\begin{array}{l}432 \text { volts to } 528 \\
\text { volts }\end{array}$ & 467 & $00 \omega$ \\
\hline \multicolumn{6}{|c|}{ Generator Bus voltage Phase B } \\
\hline $\begin{array}{l}\text { Range } 0-150 \\
\text { volts } \\
\end{array}$ & ET-EGS-B & o volts & 0 volts to 6 volts & $\cdot 2$ & Dow \\
\hline $\begin{array}{l}\text { Scale } 0-600 \\
\text { volts }\end{array}$ & & 120 volts & $\begin{array}{l}432 \text { volts to } 528 \\
\text { volts }\end{array}$ & 467 & 100w \\
\hline \multicolumn{6}{|c|}{ Generator Bus Voltage Phase $C$} \\
\hline $\begin{array}{l}\text { Range } 0-150 \\
\text { volts }\end{array}$ & ET-EGS-C & 0 volts & 0 volts to 6 volts & .8 & Dou \\
\hline $\begin{array}{l}\text { Scale } 0-600 \\
\text { volts. }\end{array}$ & & 120 volts & $\begin{array}{l}432 \text { volts to } 528 \\
\text { volts }\end{array}$ & 469 & oow \\
\hline
\end{tabular}


a

HNF-SD-C189-ATP-001

Rev. $x_{0}$

\begin{tabular}{|c|c|c|c|c|c|}
\hline Transducer & Connection Point & Test value & DCS Value & ActuaT DCS & Verified \\
\hline \multicolumn{6}{|c|}{ Panel NP-VF-I Voltage } \\
\hline $\begin{array}{l}\text { Range } 0-480 \\
\text { volts }\end{array}$ & $N A$ & 0 volts & 0 volts to 6 volts & $\lambda$ & $\infty \times$ \\
\hline $\begin{array}{l}\text { Scale } 0-480 \\
\text { volts }\end{array}$ & & 480 volts & $\begin{array}{l}432 \text { volts to } 512 \text {. } \\
\text { volts }\end{array}$ & 466,4 & oox \\
\hline \multicolumn{6}{|c|}{ Panel NP-VF-1 Frequency } \\
\hline $\begin{array}{l}\text { Range } 55-65 \\
\text { Hertz }\end{array}$ & $N / A$ & 55 Hertz & 52 Hertz to 57 Hertz & 52.5 & Doks \\
\hline $\begin{array}{l}\text { Scale 55-65 } \\
\text { Hertz }\end{array}$ & & 60 Hertz & 58 Hertz to 62 Hertz & 59,98 & oow \\
\hline
\end{tabular}




$$
\begin{gathered}
R \\
\text { HNF-SD-C189-ATṔ-001 } \\
\text { Rev. } Y_{0}
\end{gathered}
$$

Dow 2.10 Back-up Power Load Start Calls

oow 2.10 .1 Set-up 82797

Dow Verify 2721-2 switchgear load breaker 1 is OPEN, the breaker operator is disengaged and energy controls are installed.

OOW Verify 2721-Z switchgear load breakers 2, 3 and 4 are OPEN, the breaker operators are engaged and no energy control is installed.

\section{Oow 2.10.2 ATS-3 Start Call}

8.27.97

Dow Disconnect the normal ATS-3 position input (wire no. 1509) in CTBX-1.

Dow Push the 1-2-3 sequence button on the Switchgear Master Section and verify the 1-2-3 sequence light comes on.

Oow Install a jumper across the ATS-3-ES-1 and ATS-3-ES-2 contacts (start call) in CTBX-1.

Dow Verify generator I starts and breaker closes.

ODW Verify a DCS ATS3_EM alarm is received.

DOW Verify the 2721-Z switchgear load breaker operator for CB2 moves to the CLOSE position.

Dow Within about 2 minutes, verify a DCS ATS3 FL alarm is received.

DQW Disconnect jumper across the ATS-3-ES-1 and ATS-3-ES-2 contacts in CTBX-1.

Dow Verify the 2721-Z switchgear load breaker operator for CB2 moves to the OPEN position.

POW Verify Generator 1 breaker opens and generator goes into cool down.

QDW Connect the normal ATS-3 position input (wire no. 1509) in CTBX-1.

Dow 2.10 .3 ATS-4 Start Call

DW Disconnect the normal ATS-4 position input (wire no. 1511) in CTBX-1.

DOW Push the 2-3-1 sequence button on the Switchgear Master Section and verify the 2-3-1 sequence light comes on. 


$$
\begin{gathered}
\text { HNF-SO-C189-ATP-001 } \\
\text { Rev. } \text { do }_{0}^{R}
\end{gathered}
$$

Q00 Install a jumper across the ATS-4-ES-1 and ATS-4-ES-2 contacts (start call) in CTBX-1.

Dow Verify generator 2 starts and breaker closes. OOW Verify a DCS ATSA_EM alarm is received.

DW Verify the $2721-Z$ switchgear load breaker operator for CB2 moves to the CLOSE position.

QC. Within about 2 minutes, verify a DCS ATS4 FL alarm is received.

Q0 Disconnect jumper across the ATS-4-ES-1 and ATS-4-ES-2 contacts in CTBX-1.

ON Verify the 2721-Z switchgear load breaker operator for CB2 moves to the OPEN position.

DOW Verify Generator 2 breaker opens and generator goes into cool down.

Dou Connect the normal ATS-4 position input (wire no. 1511) in CTBX-1.

In Room 266 on Switchgear section 15, verify MANUAL-AUTO switch is in the MANUAL position.

Do Verify no.breaker is installed in F8X309 cubicle.

O0. Push the 3-1-2 sequence button on the Switchgear Master Section and verify the 3-1-2 sequence light comes on.

OWo Install a jumper across the 1616 and 34 contacts (start call) in switchgear master section.

Dow Verify generator 3 starts and breaker closes.

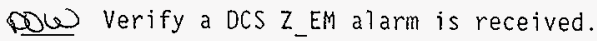

Qow Verify load breaker CB4 in the 2721-Z switchgear CLOSES.

OOW Within about 2 minutes, verify a DCS $Z_{-} F L$ alarm is received.

QQ6) Remove jumper across 1616 and 34 contacts (start call) in switchgear master section.

ONo Verify load breaker CB4 in 2721-Z switchgear OPENS.

DOW verify Generator 3 breaker opens and generator goes into cool down. 


$$
\begin{aligned}
& \text { HNF-SD-C189-ATṔ-001 } \\
& \text { ReV. } X \dot{\partial}
\end{aligned}
$$

\section{Dow 2.10.5 2736-ZB Start Cal1}

OW Verify the wiring for NP-VF-1-3 per ECN's C189-043, C189-046 and Cl89-038. (Note: Operation of NP-VF-1-3 (CB-3) cannot be checked due to the breaker providing power to 2736-ZB)

OOW Inside the Switchgear Master section, turn the 2736-ZB Transfer Test Switch to the TEST position.

Dov Verify generators 3 and 1 start and breakers close.

Qoe Verify a DCS ZB_EM alarm is received.

Dove Verify on the DCS values table that the 2736-ZB Transfer Test input is on and NP-VF-1 Bus Voltage is zero or less.

Ood Within about 2 minutes, verify a DCS ZB_FL alarm is received.

Now Return the 2736-ZB Transfer Test Switch on the Switchgear Master section to the OFF position.

Dow Verify Generators 3 and 1 breakers opens and generators go into cool down.

OOWDisconnect the normal ATS-2 position input (wire no. 1507) in CTBX-1.

QD Install a jumper across the ATS-2-ES-1 and ATS-2-ES-2 contacts (start call) in CTBX-1.

Oow Verify 3 generators start.

ODW Verify a DCS ATS2_EM alarm is received.

DDW Verify the 2721-Z switchgear load breaker operator for CB3 moves to the CLOSE position.

Dow Within about 2 minutes, verify a DCS ATS2 FL alarm is received.

Dow Disconnect jumper across the ATS-2-ES-1 and ATS-2-ES-2 contacts in CTBX-1.

Dos Verify the 2721-Z switchgear load breaker operator for CB3 moves to the OPEN position.

Douverify 3 Generator breakers open and generators go into cool down. 


$$
\begin{gathered}
R \\
\text { HNF-SO-C189-ATP-001 } \\
\text { Rev. } y 0
\end{gathered}
$$

Dow Connect the normal ATS-2 position input (wire no. 1507) in .. $92-9)$ CTBX-1. 


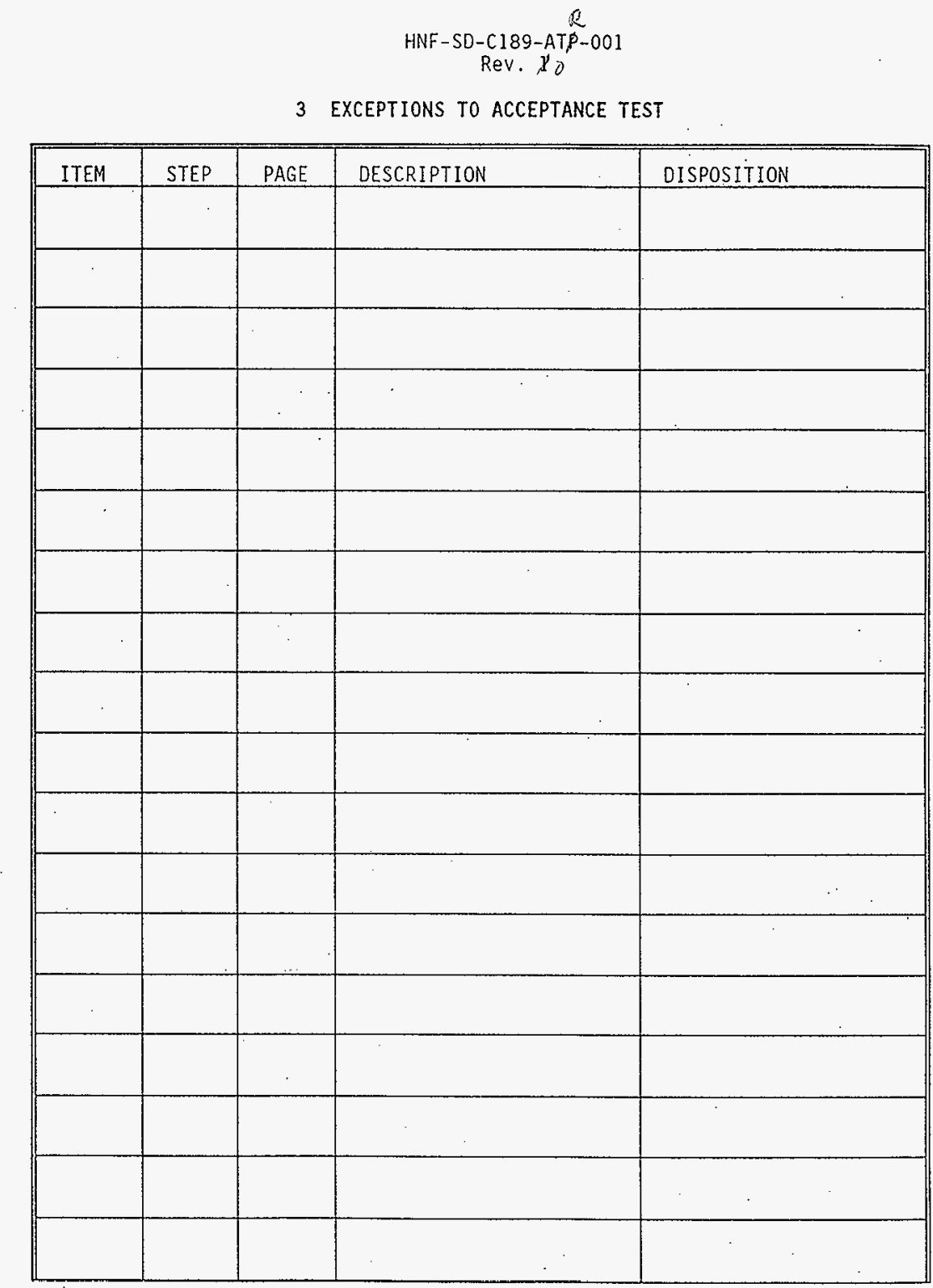




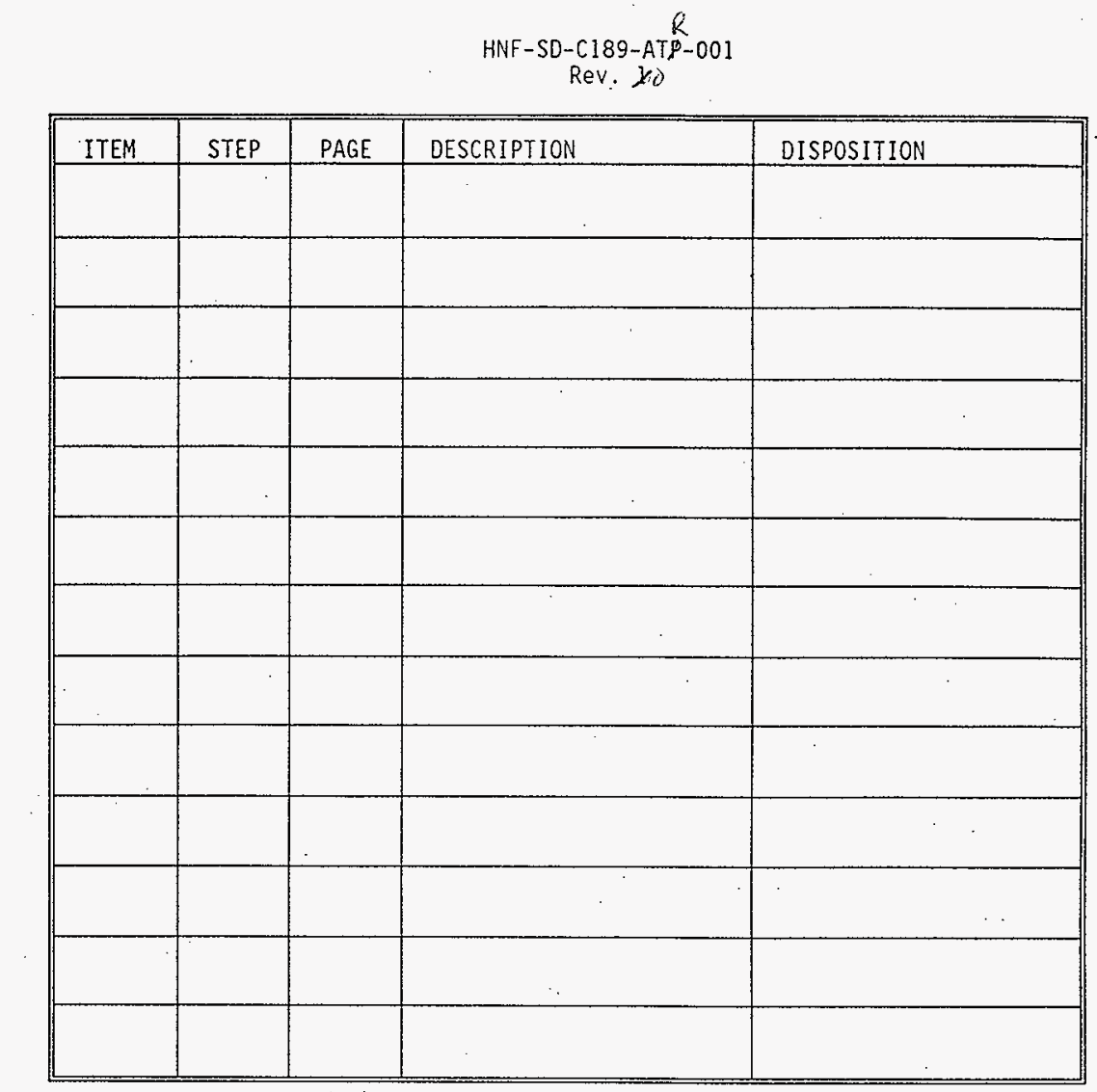


$R$

HNF-SD-C189-ATP-001

Rev. $x o$

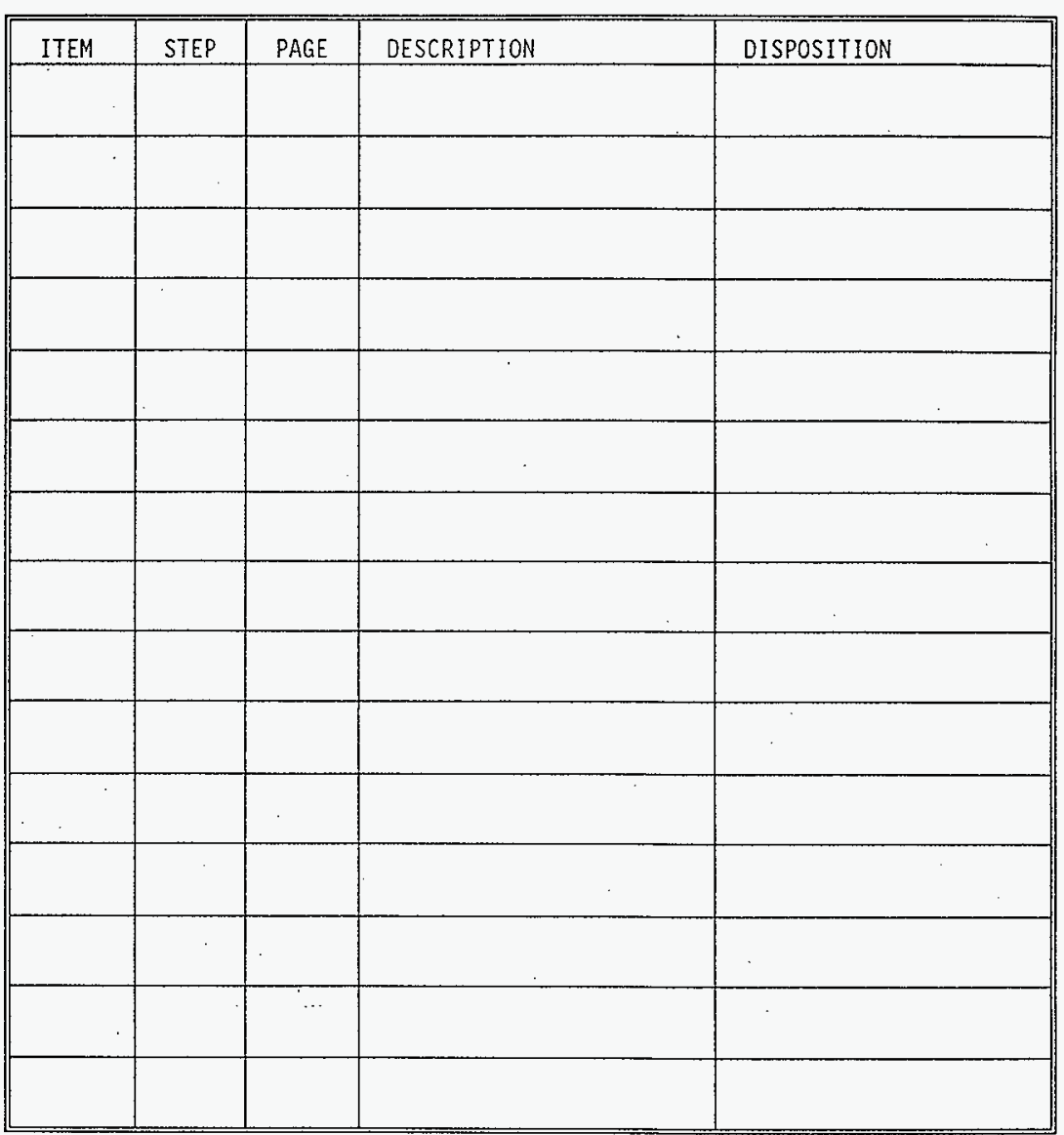




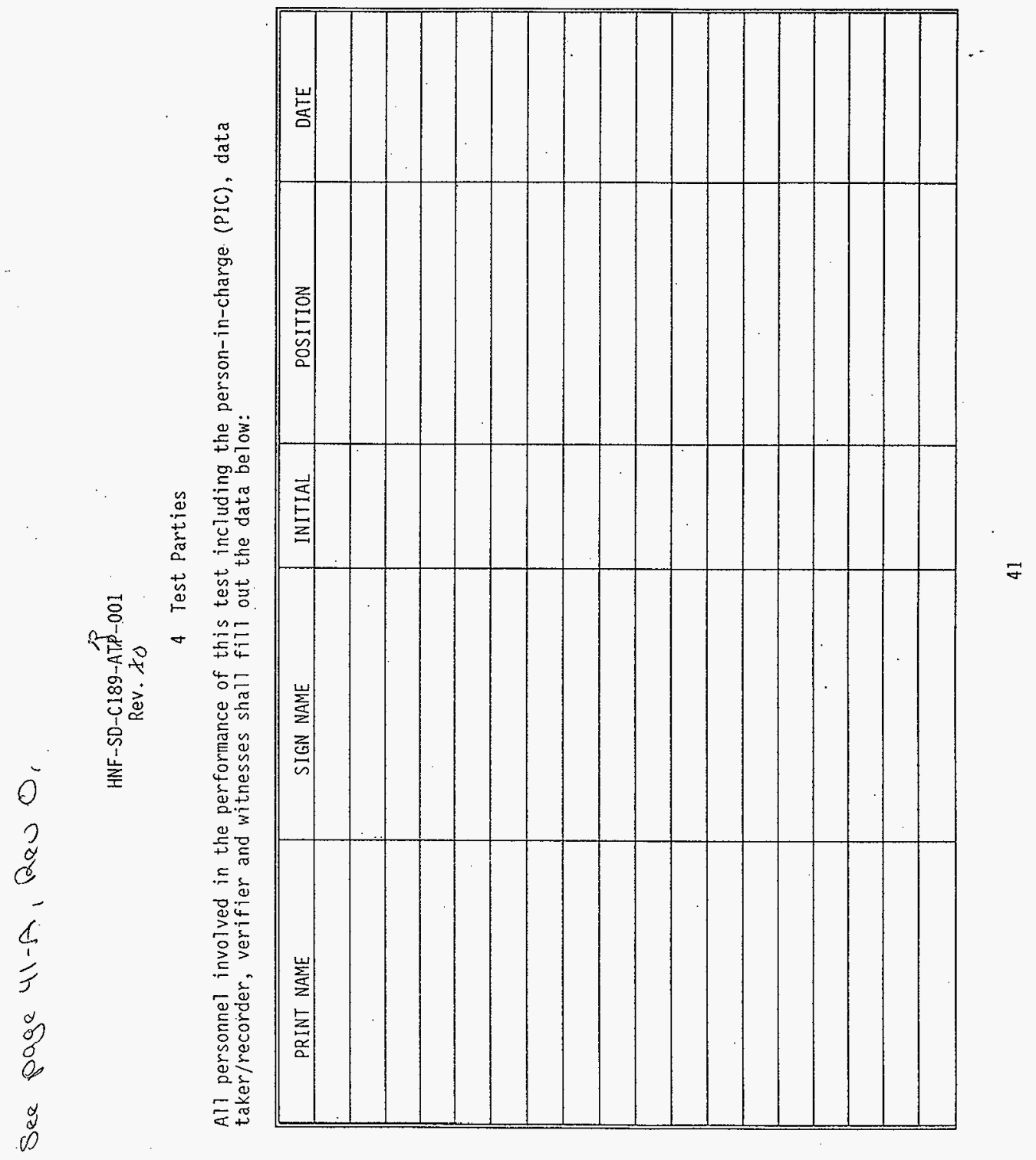




$$
\begin{aligned}
& \text { HNF-SD-C189-ALP'-001 } \\
& \text { Rev. } 0
\end{aligned}
$$

4 Test Parties

All personnel involved in the performance of this test including the person-in-charge (PIC), data taker/recorder, verifier and witnesses shall fill out the data below:

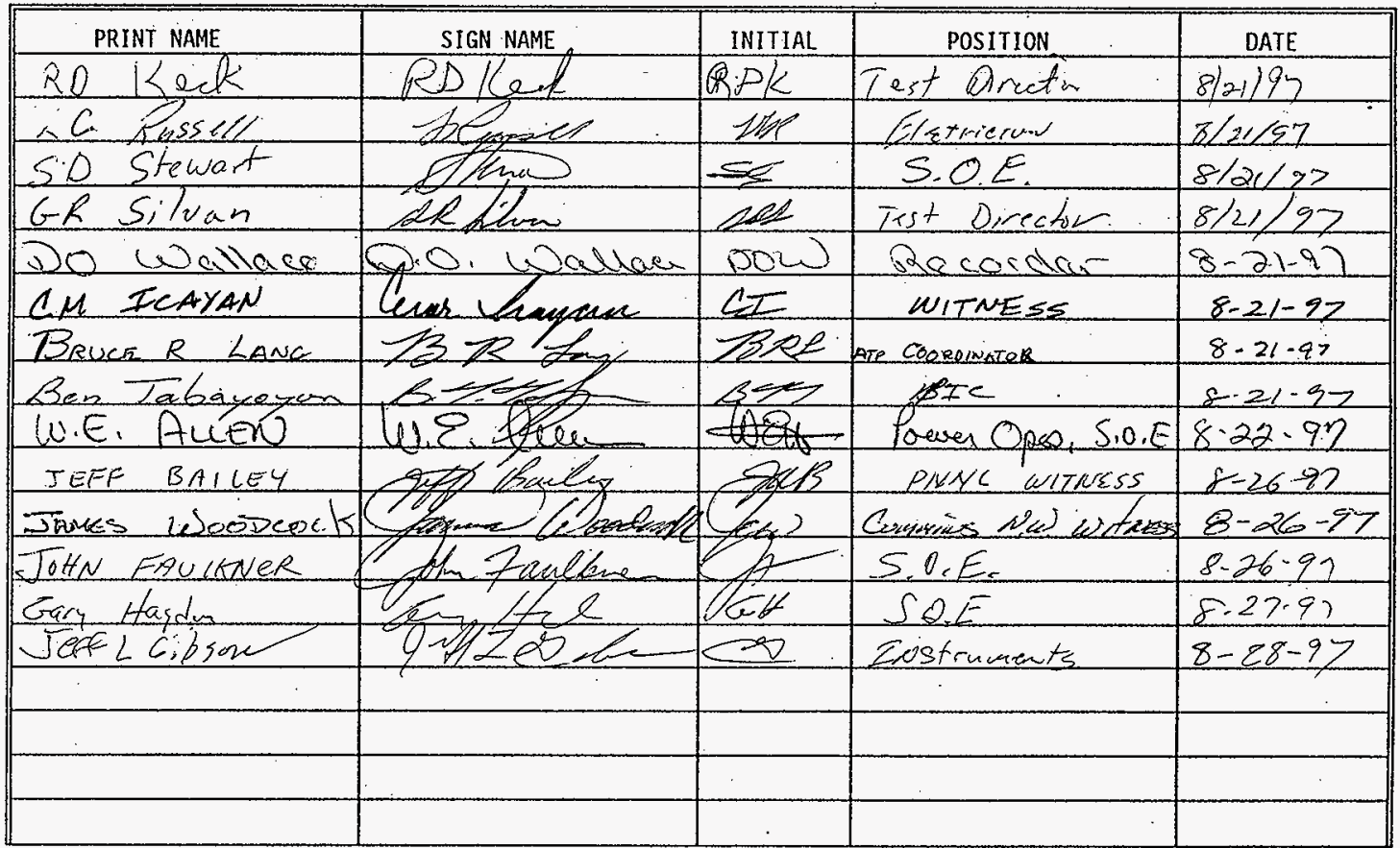

$41-A$ 
HNF-SD-C189-ATR-001 Rev. 0

\begin{tabular}{|c|c|c|c|c|}
\hline PRINT NAME & SIGN NAME & INITIAL & POSITION & DATE \\
\hline & & & & \\
\hline . & & & & \\
\hline & & & & \\
\hline & & & & \\
\hline . & & & & \\
\hline & & & & \\
\hline & & & & \\
\hline & & & & \\
\hline & & & & \\
\hline & & & & \\
\hline & & & & \\
\hline & & & & \\
\hline & & & & \\
\hline & & & & \\
\hline & & & & \\
\hline & & & & \\
\hline & & & & \\
\hline & & & & \\
\hline & & & & \\
\hline & & & & \\
\hline
\end{tabular}




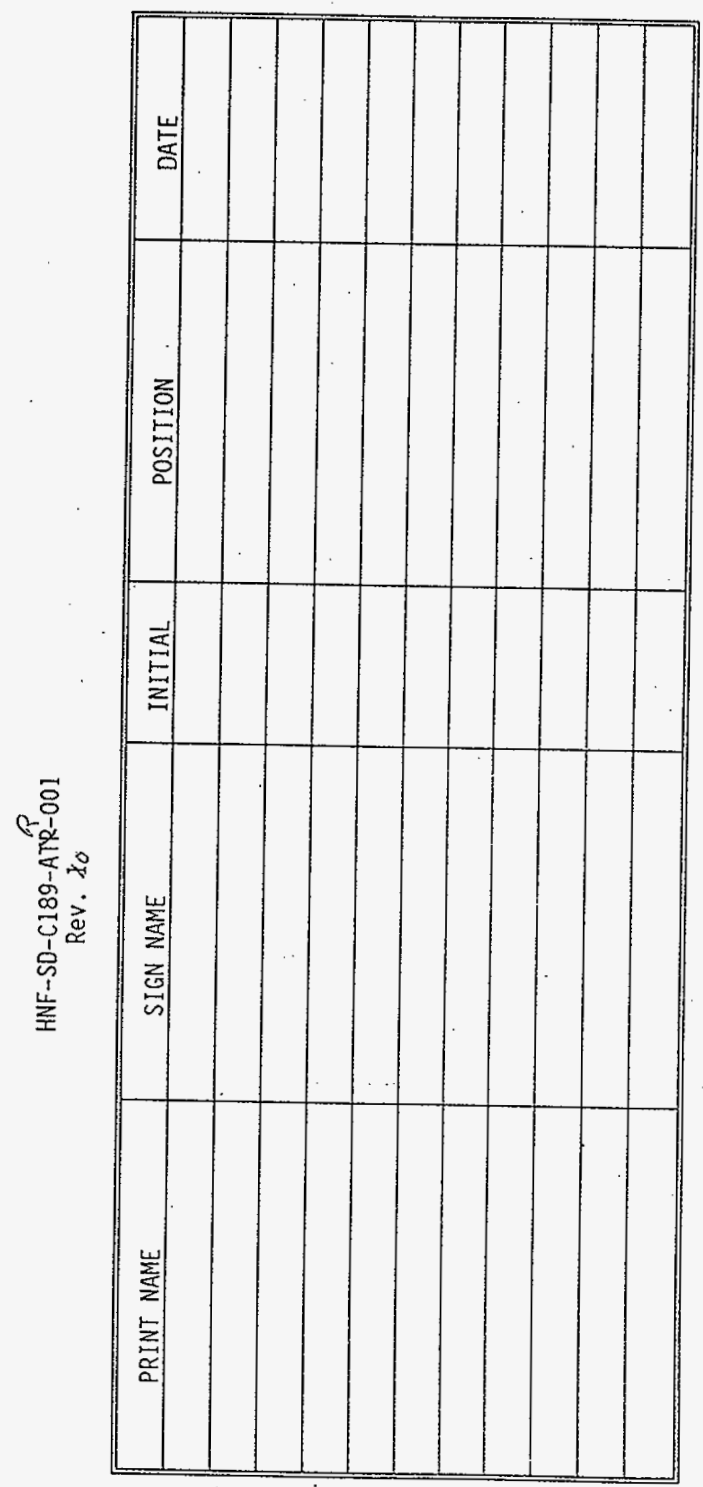




$$
\begin{gathered}
\text { HNF-SD-C189-AT } \boldsymbol{\phi}_{-001} \\
\text { Rev. } 10
\end{gathered}
$$

5 TEST APPROVAL

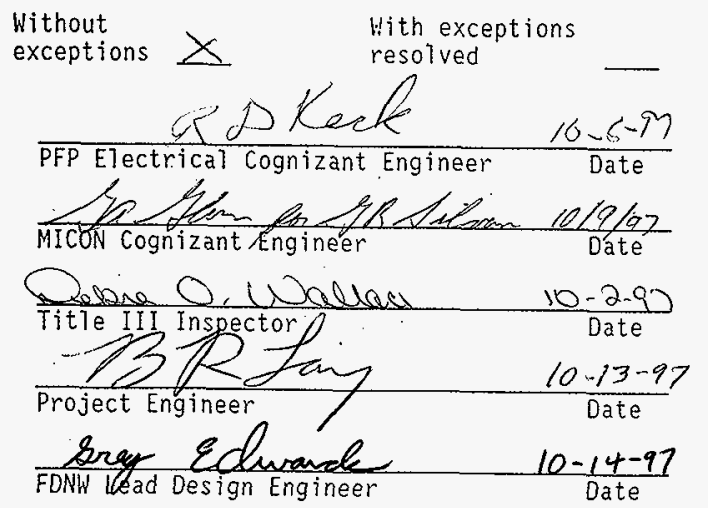

With exceptions outstanding 


\section{DISTRIBUTION SHEET}

\begin{tabular}{|c|c|c|c|c|c|}
\hline \multirow{2}{*}{$\begin{array}{l}\text { To } \\
\text { Information Resource Management }\end{array}$} & \multirow{2}{*}{\multicolumn{3}{|c|}{$\begin{array}{l}\text { From } \\
\text { PFP Facilities Systems } \\
\text { Engineering }\end{array}$}} & \\
\hline & & & & \multicolumn{2}{|c|}{ Date $11 / 14 / 97$} \\
\hline \multirow{2}{*}{\multicolumn{4}{|c|}{$\begin{array}{l}\text { Project Title/Work Order } \\
2 Z-96-2749\end{array}$}} & \multicolumn{2}{|c|}{ EDT No. 141073} \\
\hline & & & & \multicolumn{2}{|l|}{ ECN No. } \\
\hline Name & MSIN & $\begin{array}{l}\text { Text } \\
\text { With All } \\
\text { Attach. }\end{array}$ & Text Only & $\begin{array}{l}\text { Attach./ } \\
\text { Appendix } \\
\text { Only }\end{array}$ & $\begin{array}{l}\text { EDT/ECN } \\
\text { Only }\end{array}$ \\
\hline $\begin{array}{l}\text { Central Files } \\
\text { R.D. Keck } \\
\text { G.D. Anderson } \\
\text { B.R. Lang } \\
\text { B.T. Tabayoyon } \\
\text { G.R. Silvan }\end{array}$ & $\begin{array}{l}\text { A3-88 } \\
\text { T4-20 } \\
\text { T5-21 } \\
\text { T5-50 } \\
\text { T5-50 } \\
\text { T4-20 } \\
\end{array}$ & $\begin{array}{l}x \\
x \\
x \\
X \\
x \\
x \\
\end{array}$ & & & \\
\hline Project Files & $R_{1}-2 q$ & $\frac{1}{x}$ & & & \\
\hline FDNW CDC & $52-5$ & $x$ & & & \\
\hline
\end{tabular}

